to avail themselves of the aid of specialists from outside, in connection with certain of the collections. Thus the collection of the fossil foraminifera has been arranged by Prof. T. Rupert Jones, whose catalogue of the same has been recently published. Dr. Hinde has in the same way dealt with the grand collection of fossil sponges; and his illustrated catalogue of them is now in the press.

But while the purely scientific objects of the Museun are not being lost sight of, we are glad to find that the greatest efforts are being directed by the keepers to the development of the institution as a means of popular education. In addition to the three admirable guides, published at the low price of one penny each, other popular works in illustration of the collection are being prepared. Thus Mr. Fletcher has written a penny guide to the collection of meteorites, in which he has drawn up one of the best statements concerning the nature of these bodies, and of the grounds on which they are so greatly valued by scientific inquirers, that we ever remember to have read. Simple in its language and mode of treatment of the subject, this little guide is replete with the most valuable information-information which the student of the collection might ransack a library in vain to find.

Still more interesting is Dr. Woodward's venture in the same direction-an illustrated guide for the department of Geology and Palæontology. The woodcut illustrations of this work are in part original, and in part borrowed from various scientific manuals, the publishers of which have generously granted the use of them to the Museum authorities. By the aid of these woodcuts Dr. Woodward is able to call attention to the chief facts concerning the structure of some of the most remarkable fossils in the collection, and the guide forms an excellent introduction to the study of palæontology. At present the only part of this guide which is illustrated by woodcuts is that which deals with the fossil vertebrates, for these only are as yet fully arranged; but in subsequent editions, no doubt, Dr. Woodward will give equal attention to the description of the most important forms, among the invertebrates. The design is an excellent one, and there is every promise in the present instalment of the work of its being admirably carried out. Such work cannot fail to be the means of diffusing in the widest possible manner accurate notions on the subject of natural history among the people. We bope that its circulation may be as large as that of Prof. Oliver's admirably illustrated guide to Kew Gardens, which we are glad to see has passed through twenty-nine editions.

While on the subject of the means adopted by the Museum authorities to make the collections a means of diffusing correct ideas among the people, we cannot avoid referring to Prof. Owen's design of surrounding the great central hall of the building with an "Index Museum." The idea is most praiseworthy, but its execution will, we fear, be attended with serious difficulties. Prof. Owen proposes to devote the first of the six recesses on the western side of the central hall to the illustration of man, the two next to the other mammalia, the fourth to birds, the fifth to reptiles, and the sixth to fishes. On the other side three recesses are to be devoted to the invertebrata, and one each to botany, mineralogy, and geology. Few naturalists will agree with Prof. Owen that the points which distinguish man from the rest of the animal kingdom, are to the zoologist, of such importance as to necessitate the setting apart of a division of the Index Museum for their illustration; and the limited portion of the available space assigned to botany and geology will occasion much surprise. As structural alterations have interfered with the use of two of these recesses, and the liphting of some of them is far from being satisfactory, the project may perhaps have to be greatly modified. One of the recesses, that devoted to the birds, has been already arranged with instructive diagrams and well-silected specimens, and a penny guide to it, written by Prof. Owen in his well-known clear and attractive style, has been published. If the design is carried further, we hope the greatest care will be taken to make the classification and arrangement adopted in the Index Museum harmonise with that employed in the several galleries, for otherwise such a museum will not serve as an index to the great collection, but will be a source of confusiun rather than of assistance to students.

Of the zoological collections we can say little at present. The birds will occupy the ground floor of the western wing of the building, and the mammals the floor above. The osteological collections belonging to these two departments are already arranged in the upper floor, and form a new and most valuable feature of the Museum. The articulated skeletons are exhibited on the floor and in glass cases, behind which cupboards are constructed for the reception of unarticulated skeletons. The Pavilion contains a special series of bones, which are reserved for purposes of study. The skeletons of whales are to be housed in the basement of the building.

Generally we find that the convenience of the public has been fully consulted in the arrangements of the building. The lavatories and cloak-rooms are all that can be desired, but we suspect that much disappointment will be felt with regard to the refreshment department as at present constituted. Small and inconvenient counters are being erected on the highest story of the building, outside the Botanical and Osteological Galleries respectively. The obstacle thus created to the ingress and egress of visitors to those departments, and the fact that mice will infallibly be brought to them, is enough to ensure condemnation of such a plan. We hope that the trustees may yet reconsider the question, and find themselves able to devote to the purpose of refreshment, a room in the building which is centrally situated, and at the same time entirely cut off from the collections.

\section{THE COMET}

\section{$\mathrm{W}^{\mathrm{E}}$ take the following from the Sydney Morning Herald} of September 19:-

Mr. H. C. Russell, Government Astronomer, sends us the following interesting particulars respecting the comet, under yesterday's date :-

The comet discovered on the 7 th has developed in brilliance rapidly. When I first saw it on the 8 th, the nucleus was equal to a bright star of the second magnitude; by the IIth it was brighter than a first magnitude star, and I was able to see it for eight minutes after sunrise on that day. Subsequently, the mornings were cloudy, and I could not see the comet either then or during the daylight, probably because of the sea haze, which is more or less part of the N.E. wind. The comet has, however, increased in brilliance so rapidly that Mr. Ellery was able to see the comet at noon, and telegraphed to me to that effect, and the air being clear it was found at once. I had not anticipated such a wonderful increase in its light, for now it is easily seen in the full glare of the sunshine, like a star of the first magnitude, even when viewed without a telescope, and it must be many times more brilliant than Venus when at maximum. In the large telescope the nucleus appears round and well defined, and measured three seconds in diameter; from it, extended on each side, the first branches of the coma, like two little cherub wings, and in front, the great body of the coma, forming a brilliant and symmetrical head, and thence turning to form the tail six minutes long. Under close scrutiny it was evident that the coma had one or more dark bands, curved like the outline, which made the form very interesting, but the glare of the sunlight made it very trying to the eyes. It is a splendid object, and it is to be regretted that no stars can be seen by means of which to fix 
accurately the comet's position; but should the weather continue fine, it will be possible to do this with the transit instrument. $\mathrm{My}$ observations this afternoon show that the comet was moving away from the sun again, and should this be maintained, it will become a morning, not an evening object. At I.I5 p.m. to-day the comet was only $9 \mathrm{~m}$. $45 \mathrm{~s}$. west from the centre of the sun, and $7 \mathrm{~m}$. of declination south; by 5 p.m. the distance in right ascension had increased three minutes; the declination was slightly less. Unless some rapid change in the direction of the motion takes place before to-morrow (and now that the comet is so near the sun this may result), the comet will be seen without the aid of a telescope, about seven degrees west of the sun. History tells us of wonderful comets which outshone the sun; but it is usual to receive these statements after liberal discount. Nevertheless the great comet of 1843 was easily seen by spectators when it was only $1^{\circ} 23^{\prime}$ from the sun (that is, about half the distance between the comet and sun to-day at I p.m.); and at Parma the observers standing in the shade of a wall saw the comet with a tail four or five degrees in length. In Mexico, also, the comet was seen near the sun like a star of the first magnitude. It is probable, therefore, that the comet of 1843 , the brightest of this century, was brighter than the present one.

We are indebted to Mr. Jobn Tebbutt, of the Private Observatory, Windsor, for the following communications respecting the comet:-

September 16.--I succeeded in obtaining pretty good observations of the comet on the mornings of the gth and Ioth instant, but since the latter date fog and cloud have prevented observation. The following are the positions secured :-September 8d. I7h. 54m. 52S., R.A. $=9$ h. $37 \mathrm{~m}$. $7{ }^{\circ}$ os., Declination S. $=0^{\circ} 57^{\prime} 46^{\prime \prime} 4$; September 9d. I7h. $4.9 \mathrm{~m} .45 \mathrm{~s} .$, R.A. $9 \mathrm{~h} .45 \mathrm{~m} .47^{\circ} 8$ I s., Declination $\mathrm{S} .=0^{\circ} 53^{\prime}$ $36^{\prime \prime} \cdot 2$. A third position will, of course be necessary for the approximate determination of the orbit. In the absence, however, of such a determination it may safely be stated that the comet is rapidly coming into conjunction with the sun, and near its ascending node. It is not at all improbable that the comet is passing between us and the sun, and that in consequence its tail will be pointed approximately towards the earth. As we do not at present know the exact apparent track of the stranger, it would be advisable to watch the sun's disc at intervals during the next few days for a possible transit, and to look out at night for any indications of the aurora consequent on a possible near approach of the earth to the tail. It will be remembered that our passage through the tail of the great comet of I86I was markes by a general exhibition of auroral phenomena. It is highly probable that the comet will, towards the close of next week, become an imposing object in the west during the evenings. Like the recent Wells comet, this body will doubtless be well observed with the transit circle in full sunlight.

September I8.- The extraordinary interest which attaches to the comet now visible will, I trust, afford a sufficient apology for my again trespassing so soon on your valuable space. Supposing, from the rapid increase in the brilliancy of the comet that it would probably be seen in full daylight, I turned my attention to the immediate neighbourhood of the sun about Ioh. a.m. yesterday. I at once found the comet without a telescope; it was visible about four or five degrees west of that luminary as a brilliant white dagger-like object. The head was beautifully distinct, and the tail could be readily traced for about twenty minutes of arc. I succeeded in obtaining eleven absolute determinations of position with the equatorial, the approximate right ascension and declination of the last observation, I Ih. $25 \mathrm{~m}$. a.m., being respectively I Ih. $22 \mathrm{~m}$. and $1^{\circ} 10^{\prime}$ north. I attempted to observe with the transit instrument. The comet entered the field of the telescope and was at once bisected by the declination wire; but, un- fortunately, just before it reached the first transit wire it was obscured by a passing cloud and remained so till just previously to its quitting the field, when it was still found to be bisected. I trust the Melbourne observers will not fail to avail themselves of every opportunity to observe with the transit circle. If my memory serves me well I believe the history of astronomy does not furnish any previous instance of a comet being seen near the sun with the unassisted eye since the appearance of the extraordinary and well-known comet of 1843 . That body was seen at $3 \mathrm{~h}$. $6 \mathrm{~m}$. p.m. at Portland, U.S., by a Mr. Clark, and consequently in full sunlight, and its distance from the sun measured by hin with an ordinary sextant. The present comet was still plainly to be seen without the telescope at 5 h. p.m. yesterday. To-day it will probably be too nearly in a line with the sun to be seen; but on Tuesday and Wednesday it will, I think, again be visible. In the absence of any calculation I will here venture to offer one or two remarks. The comet appears, from a rough inspection of its apparent path, to be moving in a track somewhat resembling that which would be followed at this time of the year by the great comet of 1843 on its way to perihelion, and it is a significant fact that the earth is to-day almost exactly on the line of the comet's nodes, and on the ascending side of the sun. At Greenwich mean noon to-day the longitude of the arth will be $355 \frac{10}{2}$, while that of the ascending node of the great comet of I 843 is about $358^{\circ}$. It will be remembered that at the time of the appearance of the great comet of 1880 the parabolic elements of that body were found to be almost precisely those of the great comet of I 843 (see my paper read before the Royal Society of New South Wales in July, 1880)-and it was therefore considered that the two bodies were identical. It will be remembered, too, that at a discussion at one of the Royal Astronomical Society's meetings it was suggested that although the period between the returns of the conet in I 843 and 1880 was 37 years, the time of revolution inight be greatly shortened by the comet's passage through the sun's coronal atmosphere. The question therefore arises-Is the appearance of the present comet a return of the same body? Should the comet make its appearance in the west after sunset, it is quite certain that it cannot be identical with that of 1843 and 1880 ; but if it should now rapidly revolve round the sun, and make its appearance again west of that luminary, it must certainly be a comet of very small perihelion distance. Whether it is the comet of I 843 and I 880 time alone will decide. I dare say your readers will call to mind the speculation of $\mathrm{Mr}$. Proctor on the probable return of the comet of 1843 and 1880 .

P.S.-At I Ih. $35 \mathrm{~m}$. a.m. to-day (September I8) I again detected the comet with the unassisted eye. It was then about three-quarters of a degree west of the sun's western limb, and apparently moving west. In this case the comet in a few days must be again looked for in the morning sky.

The Herald writes:-The comet discovered on the 7 th instant has increased so greatly in brilliancy that it can be discerned in daylight with the naked eye. The fact was discovered by Mr. Ellery, Government Astronomer in Melbourne, at noon, and by him co imunicated to Mr. Russell; but the unusual phenomenon was observed by Mr. Tebbutt, of the private observatory, Windsor, at about Io o'clock. The authorities seem to agree that the history of astronomy does not furnish any previous instance of a comet being seen near the sun, as this is, since the extraordinary and well-known visitant of 1843 . It is probable, Mr. Russell states, that the comet may be seen about seven degrees west of the sun, from which luminary it is apparently, however, moving away; and, should this movement be maintained, it will become a morning and not an evening object.

So far the Sydney journal.

We are indebted to Sir H. Lefroy for an extract from 
the Eastern Star, published at Grahamstown, Cape Colony, in which Mr. L. A. Eddie, F.R.A.S, draws attention to the duplication of the nucleus which appears to have been first remarked at the Royal Observatory, Cape of Good Hope, on September 30, and on the same date in the United States: a day or so later European observers very generally perceived it. On the morning of September 24, at 4 h. 3om., Mr. Eddie, says: "A most glorious sight presented itself. The head of the comet had not yet risen, but a broad belt of.golden light, about two degrees in breadth, streamed upwards from the horizon to about ten degrees; and from the northern margin of this again, a thin streak of less brilliant light extended upwards to about another twelve degrees, and when the head had fully risen above the horizon at $4 \mathrm{~h}$. $43 \mathrm{~m}$. a.m., there were about $t$ wenty-five degrees in length of intensely luminous matter, stretching upwards from a still more luminous head, and inclined to the horizon at an angle of $70^{\circ}$. . . The head appeared as before, to consist of an apparently very solid though not very large nucleus, surrounded by a dense coma of no great extent, especially preceding the nucleus, and possessing no dark intervals, \&c." The weather prevented further observation at Grahamstown till the morning of October 3, when, on directing his $9 \frac{1}{2}$-inch Calver upon the nucleus, Mr. Eddie saw not one round planetary disc, as he had last seen it, but "two distinct ellipsoidal nuclei in juxtaposition, each of them brighter on the interior edge, and drawn out, as it were, towards the comet's ulterior boundary, so that their conjugate axes were about double the transverse. They closely resembled, in the inverting telescope, the flames of two candles placed the one above the other, so that the uppermost part of the lower flame almost overlapped the lower portion of the other. There was a dark rift the breadth of the transverse axes of these nuclei, extending from the hindermost one into the tail. These two nuclei were not parallel with the axis of the comet, but the foremost was drawn, as it were, to the south, or nearer to the direction in which the comet is moving." Mr. Eddie further compares the two nuclei to the doublestar $a$ Centauri when viewed through a clond with a low power. When daylight had advanced, they could be seen in the telescope perfectly free from the light of the surrounding coma. On the following morning the nuclei were distinctly divided with powers of 60 and 100 on the reflector: the preceding nucleus was larger and brighter than the other, but both were, if anything, smaller than previously.

The Natal Mercury of October 6 describes the imposing spectacle which the comet presented as it rose apparently from the Indian Ocean. The nucleus shone with a brilliancy rivalling Sirius, or even Venus, and the tail was slightly curved, and though, as dawn approached, a little diminished in length, appeared more concentrated and magnificent.

Observers who remember the great comet of 1843 , as it presented itself in the southern hemisphere, are somewhat divided in opinion as to which body to give the palm on the score of brilliancy, though most of them appear inclined to favour the former. The Emperor of Brazil, who observed the comet of 1843 close to the sun on February 28, and on the following evenings, considers it was not so remarkable for the brightness of the nucleus as the present comet, but that the tail had a much greater extent.

At Santiago, Chile, the comet was visible on September I7, some minutes before sunrise, and on the next morning could be followed until ixh. 3om. with the greatest facility without the telescope ; part of the tail near the nucleus was also visible, the northern border being much brighter than the other. On September 20, though the light of the comet had somewhat diminished, it was seen with the naker eye till Ioh. 30m. M. Niesten, Chief of the Belgian expedition for the observation of the transit of Venus, observed the comet in Chile: he found the length of the tail (northern branch) $25^{\circ}$ on September 22 , and $22^{\circ}$ on the following morning.

By the kindness of the Astronomer Royal, we learn that the comet was observed on the meridian at Melbourne on September I5, I6, and I7 civil reckoning; equatorial observations commenced on the morning of September Io: Mr. Tohn Tebbutt observed the comet the previous morning at his private observatory, Windsor, N.S.W. The Melbourne meridian observations will be of great value in the determination of the elements of the orbit prior to the comet's rush through the solar coronal region, the last one having been made only fifteen hours before the perihelion passage.

Subjoined is an ephemeris of the comet for I $8 \mathrm{~h}$. M.T. at Greenwich. It will be seen that it is now well observable on the meridian.

$$
\begin{aligned}
& \text { Fight Ascension. Declination. Distance from } \\
& \text { h. } \mathrm{m}, \mathrm{s} \text {. }
\end{aligned}
$$

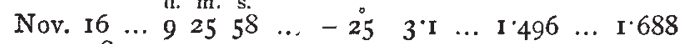

$$
\begin{aligned}
& \begin{array}{lllllllllll}
18 & \ldots & 9 & 21 & 25 & \ldots & 25 & 39^{\circ} 0 & \ldots
\end{array}
\end{aligned}
$$

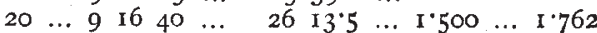

$$
\begin{aligned}
& \begin{array}{llllllllllll}
22 & \ldots & 9 & \text { II } & 43 & \ldots & 26 & 46 \cdot 4 & \ldots
\end{array} \\
& \begin{array}{lllllllllllll}
24 & \ldots & 9 & 6 & 35 & \ldots & 27 & 17 & 7 & \ldots & \text { I } 510 & \ldots & 1 \cdot 835
\end{array} \\
& \begin{array}{llllllllll}
26 & \ldots & 9 & \text { I } & 16 & \ldots & 27 & 46.9 & \ldots
\end{array} \\
& \begin{array}{llllllllllllll}
28 & \ldots & 8 & 55 & 47 & \ldots & -28 & \text { I4 } 2 & \ldots & \text { I'5 I } 4 & \ldots & \text { I } 906
\end{array}
\end{aligned}
$$

The latest investigations on the motion of this comet tend to indicate, contrary to the expectation that was at first entertained by many astronomers, that it is not identical either with the great comet of 1843 , nor with that which appeared with so great a resemblance in the elements of the orbit in I880. Calculations by Messrs. Chandler, Wendell, and Hind, are so far in accord upon this point.

\section{RECENT DYNAMO-ELECTRIC MACHINES}

FLECTRICAL inventions of innumerable kinds have E of late followed one another with bewildering rapidity; and the impetus to invention afforded by the present development of electric lighting, and by recent electrical exhibitions, is making itself felt in many ways. Most important, perhaps, of these is the production of improved types of machines for generating electric cur-

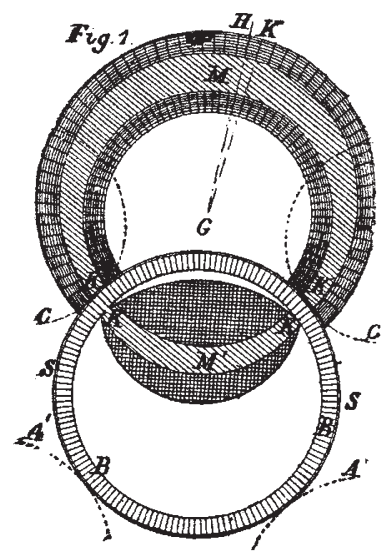

FIG. I.-Sir W. Thomson's Roller Dynamo.

rents. Dynamo-electric machines, in fact, appear to be undergoing the same kind of evolution which the steamengine has undergone; and just at present the tendency appears to be in the direction of producing larger and heavier machines than heretofore.

The readers of NATURE will be familiar with the description of Edison's large steam-dynamo, which first made its appearance in Paris in I88I, and of which two examples are now at work in the Edison installation at Holborn Viaduct. These monster dynamos, each requir- 